\title{
Multiple retinal hemorrhages in bilateral congenital venous tortuosity
}

This article was published in the following Dove Press journal:

International Medical Case Reports Journal

17 August 2017

Number of times this article has been viewed

Víctor Manuel Asensio-

Sánchez

María Soledad Rubio-

Martínez

Alba Martín-Prieto

Ophthalmology Department, Clinical University Hospital of Valladolid,

Valladolid, Spain
Correspondence: Víctor Manuel AsensioSánchez

Ophthalmology Department, Clinical University Hospital of Valladolid,

Ramón y Cajal, 3rd Street, Valladolid 47003, Spain

Tel +34983377982

Email vmasensio@yahoo.es
Abstract: We present a case of a previously healthy 52-year-old woman with acute onset of scotomas in both eyes. It was associated with headache and vomiting for the past 1 week after a cold. The best-corrected visual acuity was $20 / 20$ in both eyes. The examination of bilateral fundus revealed a venous tortuosity and mild dilatation in the posterior pole, with pre- and intraretinal hemorrhages. However, vasculatures were normally straight in the mid-peripheral and peripheral retina of both eyes. Hemorrhages showed complete resolution without treatment. There was no change in the appearance and shape of the vasculature. Ophthalmologists should be aware of congenital venous tortuosity as a possible cause of retinal hemorrhages.

Keywords: venular tortuosity, retinal vascular tortuosity, unexplained retinal hemorrhages, recurrent retinal hemorrhages

\section{Introduction}

Abnormalities in the retinal vascular pattern have been associated with systemic and retinal diseases. ${ }^{1-3}$ Various types of congenital anomalies of retinal vessels may occur, some involve the disk and the surrounding area; others may involve the entire vascular tree. ${ }^{3-6}$ The retinal vascular pattern is formed congenitally, but it is modified with the aging. Vascular tortuosity, that is, twisted blood vessels, either artery or vein, is a striking feature of the vascular pattern. Four affected family members in two generations demonstrated an unusual retinal vascular disorder called inherited retinal venous beading but with varying degrees of arteriolar tortuosity, probably autosomal dominant. ${ }^{4}$ Congenital retinal venous tortuosity is usually located at the posterior pole; most cases are unilateral, often detected during a routine eye examination, and usually do not cause visual impairment. ${ }^{7}$ To our knowledge, bilateral retinal venous tortuosity is rare. ${ }^{7}$ We report a case of multiple bilateral retinal hemorrhages as the first manifestation of congenital venous tortuosity.

\section{Clinical case}

A 52-year-old woman with no significant past medical history presented to our emergency department with a 1-week history of multiple scotomas in both eyes following headache, nausea and vomiting due to a cold. On examination, her visual acuity was $20 / 20$ in both eyes. No significant finding was observed on anterior segment examination. Intraocular pressure was $15 \mathrm{mmHg}$ bilaterally. She had no afferent pupillary defect and had normal color vision and brightness perception in both eyes. Ophthalmoscopy revealed multiple intra- and preretinal hemorrhages with tortuosity of the 
second- and third-order venules in the posterior pole area and mild dilatation in large veins in both eyes (Figure 1). No retinal thickening or exudates were noted. The patient's retinal hemorrhages were managed conservatively. On follow-up, 2 months after the initial visit, ophthalmoscopy showed complete resolution of the retinal hemorrhages (Figure 2). The patient refused fluorescein angiography. Extensive work-up failed to demonstrate the origin of the retinal hemorrhages. Muscular dystrophy, renal disease pathology, beta-thalassemia or endocrinopathy was excluded. These entities have been associated with increased retinal venous tortuosity. In the following months, the patient did not suffer from new retinal hemorrhages, and the shape of the venules was unchanged. We recorded the family history and examined the fundus of first-degree relatives. No abnormality was observed. The authors confirm that written informed consent has been provided by the patient to have the case details and any accompanying images published.

\section{Discussion}

Tortuosity of small retinal arteries and veins is a common finding during ophthalmoscopic examination, due to their easy accessibility. Increased vascular tortuosity of the retina is associated with aging, diabetes, hypertension and genetic disorders. ${ }^{1-3}$ A genetic cause of retinal tortuosity has been

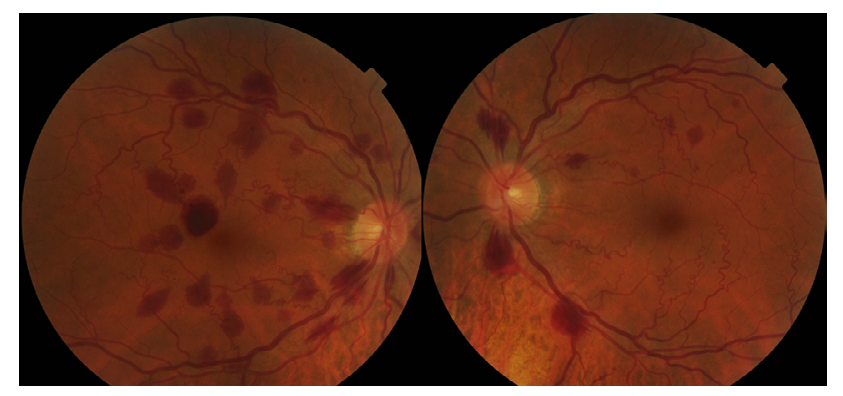

Figure I Fundus photo on presentation showing bilateral tortuosity of the small venules and multiple intra- and preretinal hemorrhages.

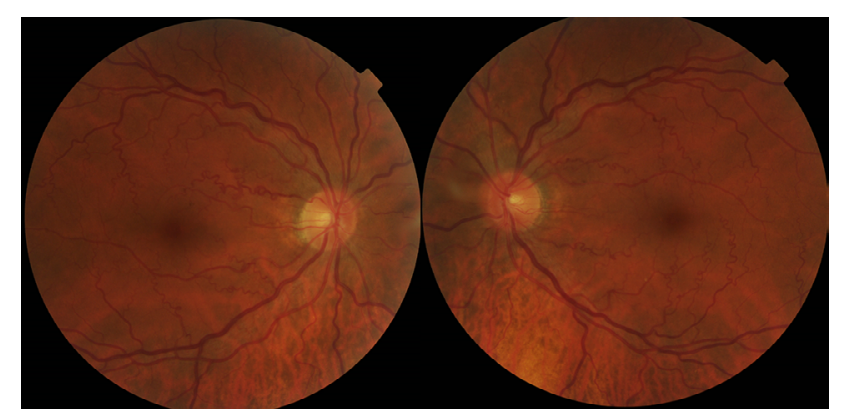

Figure 2 Fundus photo after 2 months without treatment showing complete reabsorption of the hemorrhages. recently identified: mutations in collagen, type IV, alpha 1 (COL4A1), a major component of basement membranes. ${ }^{8}$ It may be generalized or localized, affecting one or both eyes. Arterial retinal tortuosity is twice as common as venous tortuosity. ${ }^{3}$ Clinical and experimental studies have demonstrated association between vessel tortuosity and mechanical factors, such as blood pressure, blood flow, axial tension and wall structural changes. ${ }^{9}$ Vein pressure has also been associated with tortuosity in retinal veins. ${ }^{9}$ On the other hand, tortuosity increases the resistance to blood flow, and severe tortuosity can obstruct or even occlude blood flow. ${ }^{9-11}$ Congenital venous tortuosity shows a characteristic pattern of tortuosity. ${ }^{7}$ Only the venules of second and third order show tortuosity with corkscrew and spiral shapes. The caliber of the large veins shows mild dilatation. Venous changes are evident in macular and perifoveolar area, whereas the periphery is not affected. The arterial system is normal. No severe complication had been reported previously and normally is asymptomatic. In addition, our patient had no specific underlying complications that contributed to the development of this vascular anomaly; all this evidence shows that this case is a congenital one rather than acquired. Tortuosity increases the flow resistance and may also activate platelets and consequently induce thrombosis in microvessels. ${ }^{9-11}$ In the current report, multiple retinal hemorrhages occurred in association with the valsalva maneuver (nausea and vomiting): intraabdominal or intrathoracic pressures could increase central venous pressure allowing direct transmission into the head because of the absent valves in the venous system of the neck and head. Sudden elevations of venous pressure cause a decompensation in the retinal capillary bed with retinal hemorrhages that rarely break into the vitreous. ${ }^{12}$ The risk does not seem to be associated with the severity of the tortuosity. Hemorrhages can occur spontaneously, or after relatively minor trauma. Vision returns to normal after blood reabsorption occurred, and as in the current report no treatment is necessary. Our patient refused fluorescein angiography, but does not provide any additional information of diagnostic value in congenital venous tortuosity. There are other conditions secondary to retinal vascular and systemic diseases that share similar venous characteristics, and hence must be differentiated from congenital venous tortuosity as predominantly venous tortuosity due to venous congestion (cardiopulmonary disease, central retinal vein occlusion, primary antiphospholipid syndrome and hyperviscosity syndromes), retinal ischemia (high-altitude and diabetic retinopathy) and fetal alcohol syndrome. ${ }^{12}$ Many of these conditions present with additional ocular and systemic 
findings which can assist in determining the diagnosis. Congenital venous tortuosity may be asymptomatic if it does not involve the fovea. Typical cases can easily be diagnosed by ophthalmoscopy, and the hemorrhages tend to be absorbed spontaneously in a short period without any complication. This report highlights the importance of maintaining a high index of suspicion in patients with congenital venous tortuosity as a possible cause of retinal hemorrhages.

\section{Disclosure}

The authors report no conflicts of interest in this work.

\section{References}

1. Hayreh SS, Servais GE, Virdi PS. Retinal arteriolar changes in malignant arterial hypertension. Ophthalmologica. 1989;198(4):178-196.

2. Taarnhøj NC, Munch IC, Sander B, et al. Straight versus tortuous retinal arteries in relation to blood pressure and genetics. $\mathrm{Br} J$ Ophthalmol. 2008;92(8):1055-1060.
3. Gauss H. Normal and abnormal development: congenital deformities In: Duke-Elder S, editor. System of Ophthalmology. Vol. III. St. Louis, MO: Mosby; 1964:723-726.

4. Stewart MW, Gitter KA. Inherited retinal venous beading. Am J Ophthalmol. 1988;106(6):675-681.

5. Giuffrè G, Lodato G. Prepapillary venous loops and choroidal veins tortuosity. Acta Ophthalmol Scand. 2003;81(6):665-666.

6. Stelson KA, Blackshear PL Jr, Wirtschafter JD. On the tortuosity of the veins of the retina. Microvasc Res. 1983;26(1):126-128.

7. Xu N, Cui Y, Gao Z. Bilateral congenital venous tortuosity and dilatation combined with cilioretinal artery: a photographic essay. Int Med Case Rep J. 2016;9:91-93.

8. Alavi MV, Mao M, Pawlikowski BT, et al. Col4a1 mutations cause progressive retinal neovascular defects and retinopathy. Sci Rep. 2016;6:18602.

9. Han HC. Twisted blood vessels: symptoms, etiology and biomechanical mechanisms. J Vasc Res. 2012;49(3):185-197.

10. Khan J, Chong V. Two retinal vein occlusions in a patient with venous tortuosity at the optic disc. Graefes Arch Clin Exp Ophthalmol. 2007;245(2): 313-314.

11. Awan KJ. Anomalies of the retinal veins and their incidence. $J$ Pediatr Ophthalmol. 1976;13(6):353-359.

12. Sutter FK, Helbig H. Familial retinal arteriolar tortuosity: a review. Surv Ophthalmol. 2003;48(3):245-255.
International Medical Case Reports Journal

\section{Publish your work in this journal}

The International Medical Case Reports Journal is an international, peer-reviewed open-access journal publishing original case reports from all medical specialties. Previously unpublished medical posters are also accepted relating to any area of clinical or preclinical science. Submissions should not normally exceed 2,000 words or
Submit your manuscript here: https://www.dovepress.com/international-medical-case-reports-journal-journal

\section{Dovepress}

4 published pages including figures, diagrams and references. The manuscript management system is completely online and includes a very quick and fair peer-review system, which is all easy to use. Visit $\mathrm{http}: / / \mathrm{www}$. dovepress.com/testimonials.php to read real quotes from published authors. 